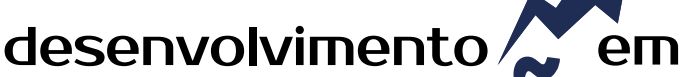 QUESTÂO
}

\section{GESTÃO SOCIAL, PARTICIPAÇÃO E TERRITÓRIO: o Caso do Distrito Califórnia no Município Barra do Piraí-RJ}

\author{
http://dx.doi.org/10.21527/2237-6453.2021.56.10562
}

Recebido em: 15/4/2020

Aceito em: 13/5/2021

Thais Soares Kronemberger, ${ }^{1}$ Ana Claudia Pedrosa de Oliveira, ${ }^{2}$ Beatriz Jullie Batista de Sousa ${ }^{3}$

\begin{abstract}
RESUMO
O artigo tem como foco analisar a participação social durante o processo de anexação do distrito Califórnia, em Barra do Piraí, ao município de Volta Redonda, ambos localizados na microrregião do Vale do Paraíba, no Estado do Rio de Janeiro. Busca-se problematizar a dinâmica participativa sobre a nova conformação territorial acerca dos anseios dos moradores pela anexação. A revisão bibliográfica parte da discussão sobre participação entendida como um processo de conquista relacionado à mobilização e organização social na reivindicação de interesses coletivos específicos e de direitos. O território, desta forma, constituiria um espaço com identidade, compreendido não somente como uma realidade geográfica ou física, mas uma realidade humana, social, cultural e histórica. Por sua vez, a gestão social é definida por uma relação dialógica, participativa, entre os atores sociais no território tendo por finalidade discutir sobre as problemáticas comuns e deliberar a respeito das ações a serem estabelecidas em prol do bem comum. A metodologia da pesquisa, de natureza qualitativa e do tipo exploratória, adota o método do estudo de caso único tendo a coleta de dados sido realizada por pesquisas bibliográfica, documental e de campo. $O$ tratamento dos dados seguiu a análise de conteúdo com a definição de categorias por grade mista. Os resultados apontam que a anexação legitimaria o anseio da população local em pertencer ao município com maior proximidade geográfica, mas, principalmente, com melhor provisão de serviços públicos.
\end{abstract}

Palavras-chave: participação social; território; gestão social.

\section{SOCIAL MANAGEMENT, PARTICIPATION AND TERRITORY: THE CASE OF CALIFORNIA DISTRICT IN BARRA DO PIRAII-RJ}

\begin{abstract}
The article focuses on analyzing the social participation during the process of annexation of the California District, in Barra do Piraí, to the municipality of Volta Redonda, both located in the Vale do Paraíba microregion, in the state of Rio de Janeiro. Seeks to problematize the participatory dynamics about the new territorial conformation about the residents' desires for annexation. The bibliographic review starts from the discussion about participation, understood as a process of achievement related to mobilization and social organization in the claim of specific collective interests and rights. The territory, in this way, would constitute a space with an identity understood not only as a geographical or physical reality, but a human, social, cultural and historical reality. In turn, social management is defined by a dialogical, participatory relationship between social actors in the territory with the purpose of discussing common issues and deliberating on actions to be established for the common good. The research methodology, of qualitative nature and exploratory type, adopts the method of the single case study and the data collect was performed by bibliographic, documentary and field research. Data treatment followed content analysis with the definition of categories by mixed grid. The results show that the annexation would legitimize the desire of the local population to belong to the municipality with greater geographical proximity, but, mainly, with a better provision of public services.
\end{abstract}

Keywords: social participation, Territory; social management.

\footnotetext{
${ }_{1}^{1}$ Autora correspondente. Universidade Federal Fluminense (UFF) - Instituto de Ciências Humanas e Sociais. Rua Desembargador Ellis Hermydio Figueira - Aterrado. Volta Redonda/RJ, Brasil. CEP 27213-145. http://lattes.cnpq.br/1581120377467873. thaisskron@ yahoo.com.br

${ }^{2}$ Universidade Federal do Amazonas (Ufam). Faculdade de Estudos Sociais. Manaus/AM, Brasil.

${ }^{3}$ Universidade Federal Fluminense (UFF). Instituto de Ciências Humanas e Sociais. Volta Redonda/RJ, Brasil.
} 


\section{INTRODUÇÃO}

O artigo insere-se na temática sobre territorialização e participação social no âmbito municipal e tem como objetivo analisar a atuação da população local durante o processo de anexação do distrito Califórnia em Barra do Piraí a Volta Redonda, ambos municípios localizados na microrregião do Vale do Paraíba, no Estado do Rio de Janeiro. Tal processo culminou no Projeto de Lei $733 / 2011$, que se manteve em evidência nas agendas dos municípios em tela e também do Estado durante o período de 2011 a 2016, tendo sido marcado pela expressiva participação dos moradores no desejo comum pelo desmembramento municipal.

Anexação é um termo ainda pouco discutido no âmbito do Campo de Públicas, sendo definida pela adesão, por um município, de um bairro ou distrito desmembrado de uma outra municipalidade. Esse processo, ao ser analisado de maneira transcendente aos aspectos legais, possibilita compreender as motivações que estimulam a população envolvida a querer pertencer a outro espaço.

Questões acerca do processo de formação territorial devem considerar aspectos sociais, culturais, econômicos e históricos na construção do território e no cotidiano, de maneira individual e específica a cada localidade (RAFFESTIN, 1993). Isso contribui para o entendimento de que cada espaço possui suas próprias características, necessidades e realidade, de forma que seus indivíduos sintam-se parte deste à medida que são atendidas suas demandas e construídas suas relações. O território, portanto, é considerado um espaço com identidade; sendo percebido como uma construção social e não um espaço predeterminado, "objetivamente existente" e derivado de características físicas ou econômicas (SCHEJTMAN; BERDEGUÉ, 2004).

As necessidades e demandas da sociedade civil podem ser conquistadas a partir da maior participação nos espaços públicos e do engajamento coletivo tendo em vista que a coletividade possui uma voz mais ativa e expressiva se comparada à luta individual. A prática da participação aponta para a dificuldade em se conquistar soluções isoladamente, tornando imprescindível a construção de decisões colegiadas pela sociedade (TENÓRIO; ROZENBERG, 1997).

Dessa maneira, a participação constitui um elemento-chave para a inserção da sociedade no processo político decisório em questões relacionadas ao desenvolvimento do território (TENÓRIO, 2011). Esta ação gerencial dialógica e participativa, em que o processo decisório é exercido de forma compartilhada e deliberada entre os diferentes atores envolvidos denomina-se gestão social. Como explica Tenório (2008a), "o adjetivo social qualificando o substantivo gestão será entendido como espaço privilegiado de relações sociais no qual todos têm direito à fala, sem nenhum tipo de coação" (p. 158).

Sustentado em tal referencial, a pesquisa desdobra-se em quatro objetivos específicos: (i) apresentar a trajetória de mobilização e organização social, a partir da percepção dos moradores integrantes das associações de bairros, no processo de anexação do distrito Califórnia ao município de Volta Redonda; (ii) evidenciar a atuação do poder público municipal em relação ao pleito dos moradores pela nova conformação territorial; (iii) caracterizar a relação dos moradores do distrito Califórnia com o município de Volta Redonda-RJ; (iv) identificar os principais desdobramentos provenientes do processo de anexação para o distrito Califórnia.

Para tanto, o texto encontra-se estruturado em cinco seções além desta introdução e das referências bibliográficas. A seguir, discute-se o referencial bibliográfico com base nos temas 
geradores desta pesquisa, a saber: território e participação social. A terceira seção discorre sobre o conceito de gestão social adotado neste estudo. Em seguida, a metodologia da pesquisa é apresentada com foco nas técnicas de coleta e análise dos dados. A quinta seção discute os resultados a partir das categorias de análise elaboradas à luz do referencial bibliográfico e da pesquisa de campo. Por fim, as considerações finais são tecidas com base na questão central do estudo sobre a dinâmica do processo participativo que culminou com a criação do Projeto de Lei 733/2011 pela anexação do distrito Califórnia ao município de Volta Redonda-RJ.

\section{INTERFACES ENTRE TERRITÓRIO E PARTICIPAÇÃO SOCIAL}

A noção de território compreende um leque de várias definições e sentidos que o caracterizam como um conceito polissêmico por excelência, pois leva em consideração as múltiplas dinâmicas - econômicas, sociais, políticas e culturais - endógenas a cada território, relacionadas à sua história local (BONNAL; DELGADO; CAZELLA, 2011; CAZELLA; BONNAL; MALUF, 2009).

O conceito de território guarda relação com a noção de pertencimento dos atores tendo como fundamento o espaço por meio de um processo de construção e de relações entre os indivíduos. Tal dinâmica é responsável pela formação da identidade territorial constituída por aspectos sociais, culturais, econômicos e históricos no processo de territorialização (RAFFESTIN, 1993). Pode-se afirmar que o "território significa apropriação social do ambiente; ambiente construído, com múltiplas variáveis e relações recíprocas" (SAQUET, 2008, p. 81).

A especificidade de um território está no entendimento entre "território dado" e "território construído". O primeiro é considerado uma porção do espaço que é objeto de observação; preexistente, no qual não há preocupação em analisar sua origem e as condições de sua constituição. Já o território construído é resultado de um processo de formação pelos atores e, com isso torna-se peculiar, único, ao possuir características próprias (PECQUEUR, 2005).

Por outro lado, é importante considerar que um "território dado", constituído por uma unidade político-administrativa, pode abrigar diversos "territórios construídos", ou seja, "o território pode ser visto como uma configuração mutável, provisória e inacabada, e sua construção pressupõe a existência de uma relação de proximidade dos atores" (CAZELLA; BONNAL, MALUF, 2009, p. 37).

O território, portanto, não deve ser considerado como algo a priori, mas como o resultado de um processo de construção, da organização dos atores, de suas estratégias para enfrentar desafios e criar oportunidades, como também de fenômenos oriundos da aprendizagem coletiva. "Conviene pensar más en términos del territorio como un recurso construido a partir de practicas concretas y comportamientos identificables" (MADOERY, 1999, p. 7).

Nesse sentido, o território é considerado uma unidade ativa do desenvolvimento, possuidora de recursos específicos e não transferíveis de um lugar para outro. São recursos materiais e imateriais, como um saber-fazer original, relacionado à história local. Assim sendo, o território não é apenas uma realidade geográfica ou física, mas uma realidade humana, social, cultural e histórica (CAZELLA; BONNAL; MALUF, 2009, p. 37).

Pela noção de territórios "dado" e "construído" é possível compreender a limitação e a concepção das fronteiras geográficas em que são dispostos e cuja finalidade é a marcação do espaço e das relações de poder. Essas marcações podem tanto gerar quanto evitar conflitos en- 
tre os territórios divididos, principalmente por conta das relações existentes e das trocas entre os atores em busca de desenvolvimento de acordo com seus interesses (RAFFESTIN, 1993).

O território nasce com uma dupla conotação, seja material, como próximo de terra, seja simbólica, em termos de dominação (jurídico-política) do espaço. Nesse sentido, a compreensão de território também guarda relação com o exercício do poder em um sentido mais concreto, de relações de dominação, de apropriação do espaço construído socialmente. Isso torna os territórios distintos, pois são os sujeitos que efetivamente exercem o poder e que de fato controlam determinado espaço e, por consequência, os processos sociais que conformam o território (HAESBAERT, 2004).

A atuação dos atores pertencentes a um espaço geográfico possui relação direta com a construção de um território, constituindo produto de um processo de melhoria, fruto do jogo de atores. Este processo busca recursos específicos, latentes, a serem organizados, explorados ou revelados que caracterizam e especificam um território. Trata-se de uma dinâmica de mobilização e arranjos dos atores, frequentemente em torno de um problema comum (PECQUEUR, 2005).

Neste sentido, a participação constitui um elemento presente na dinâmica territorial e pode ser compreendida como "fazer parte", "tomar parte" ou "ter parte" (BORDENAVE, 1983); é um constante vir-a-ser, sempre fazendo, nunca interpretada como uma concessão, doação ou algo preexistente. Também não pode ser entendida como dádiva porque não seria produto de conquista. Não pode ser compreendida como concessão porque não é fenômeno residual da política social (DEMO, 1988).

"Participar" assume um sentido essencialmente político, sustentado na sociedade civil e caracterizada como uma atividade de interação com o Estado na conquista de direitos. Ou seja, a participação aqui entendida possui objetivos amplos e não é reduzida à mera prestação de serviços à comunidade, à organização isolada dos segmentos sociais ou até mesmo ao atendimento de interesses específicos, apesar de tais elementos também fazerem parte do processo participativo (TEIXEIRA, 2002).

Importante perceber que ao conceituar a participação, diversas dimensões podem ser assumidas pelo participante. Entre tais dimensões destacam-se: (1) expressão política e social; (2) decisão política; (3) pedagógica e (4) exercício do controle social. Estabelecer dimensões para a participação não quer dizer que se deva valorizar polarizações, por exemplo, "participação como expressão" ou "participação como decisão", mas sim considerar um conjunto de significados como forma de fortalecer e aprofundar a democracia.

A participação como forma de expressão detém caráter mais simbólico, valorativo e caracteriza-se por marcar presença no cenário político, mesmo que não cause nenhum impacto ou influencie decisões (TEIXEIRA, 2002). É o caso, por exemplo, das mobilizações sociais, da ocupação dos espaços públicos por movimentos sociais como forma de expressão política, cultural, social, mas, sobretudo, de reconhecimento pelos demais das suas necessidades e ideologias que formam a sua identidade como grupo.

Já a participação com decisão política diz respeito a uma forma organizada, não episódica, em que os atores que compõem a sociedade civil intervêm politicamente no processo decisório. A participação assume o papel de ser instrumento de poder da sociedade pelo Estado, tendo os cidadãos a possibilidade de definir critérios para orientar a ação pública (TEIXEIRA, 2002). 
A terceira a ser mencionada diz respeito à dimensão pedagógica da participação. Pode ser compreendida pelo significado de "fazer parte"; "tomar parte"; "ser parte" de um ato ou processo, de uma atividade pública, de construção de ações coletivas. Ao se referir como "parte", a participação implica pensar no coletivo, na sociedade, no Estado, em que, não sendo algo homogêneo, se fazem sentir distintos interesses, valores e formas de poder (TEIXEIRA, 2002).

Por fim, a participação também remete ao exercício do controle social a partir de dois elementos basilares: a noção de accountability, que quer dizer a obrigação dos agentes públicos de prestarem contas de seus atos e decisões, assim como o direito do cidadão de exigi-los e avaliá-los; e a ideia de responsabilização pelos atos praticados em nome da sociedade, conforme padrões legais e éticos (TEIXEIRA, 2002).

Importante salientar que a participação assim compreendida permite o alcance da emancipação social ao estabelecer a centralidade do sujeito social no espaço histórico e, com isso, reduzir as desigualdades. Para ser atingida, alguns elementos prévios, mas que são constituintes da participação, tornam-se necessários, como: deve-se perceber a participação como processo, denotando que se trata de um fenômeno historicamente dinâmico; não constitui obra de terceiros, mas dos reais interessados e, por isso, é necessário um esforço de conquista e construção do processo participativo; aliado a esse esforço, está a constituição de organização, com um dos instrumentos para atuação do cidadão no âmbito coletivo e não individual; e, como ápice dessa sequência, tem-se a emancipação social, que promove a transformação social ao ser assumida como projeto político pelos próprios desiguais (DEMO, 1991).

De forma geral, no âmbito da administração pública, parte-se do pressuposto de que só quem está inserido na realidade local tem habilidades para apontar os problemas vividos, de forma a contribuir para a formação de ações públicas que atendam adequadamente à sociedade, além de influir nos processos decisórios. Para tanto, a sociedade busca encontrar seu espaço de influência mediante formas variadas de organização social, da abertura de novos canais de participação, do incremento na interação com o âmbito governamental e da assimilação de instrumentos de gestão social que tornem suas ações mais eficazes (TENÓRIO; ROZENBERG, 1997).

\section{GESTÃO SOCIAL: DISCUSSÃO CONCEITUAL}

Gestão social é um conceito recente (MAIA, 2005; BOULLOSA; SCHOMMER, 2010) e em construção (CANÇADO; TENÓRIO; PEREIRA, 2011; FRANÇA FILHO, 2008), direcionado para estudos sociopolíticos de organizações e interorganizações a partir de uma orientação sociocêntrica (COELHO, 2015).

No campo da Administração, "gestão" é entendida como um processo que visa ao uso racional dos recursos com fins econômicos. $O$ uso corrente do termo está associado à sujeição do indivíduo ao processo de acumulação de capital quando inserido na produção e reprodução de riquezas materiais. De forma contrária, a "gestão social" está relacionada a uma nova visão que se distancia do capital e reconhece a sociedade civil como protagonista, juntamente com o Estado, no papel de planejar e tomar decisões capazes de promover o desenvolvimento orientado para o bem-estar comum (CARRION; CALOU, 2008).

Isso porque a visão tradicional da gestão sempre enfatizou a dimensão da capacidade técnica, sobretudo as qualidades de planejamento racional. A partir dessa perspectiva, a dimensão 
da interação humana fica ausente, pois a gestão é exercida por pessoas qualificadas, notáveis, que detêm cargos de direção/coordenação no interior de seus gabinetes ou escritórios. Por isso que, ao introduzir a expressão "gestão social", uma mudança e uma desconstrução do significado de gestão são provocadas na geração do pensamento da Administração (FRANÇA FILHO, 2008).

O contexto histórico de introdução do tema durante a década de 90 do século 20 está associado a dois processos conflituosos que marcam a contemporaneidade: o primeiro diz respeito ao fenômeno da globalização, que mercantiliza e amplia os segmentos de atuação do capital na sociedade, incluindo a redução da atuação do Estado e o predomínio das estratégias de mercado; o segundo refere-se à conquista tardia dos direitos sociais, refletida na dimensão da cidadania e na constituição de um Estado Democrático de Direito que preconiza a descentralização e a participação social como diretrizes das políticas sociais (MAIA, 2005).

Pode-se concluir, dessa maneira, que, se de um lado há "gestão contra o social", na qual predominam os valores e propósitos do capital no campo societário direcionados por uma racionalidade instrumental e mercantil, do outro há o esforço de uma "gestão com social", sedimentada em valores democráticos e de cidadania e que reconhece a sociedade como sujeito político de transformação social (MAIA, 2005).

"A gestão social busca uma sociedade mais justa e democraticamente articuladora na gestão dos seus interesses, que não os do mercado, enclave da sociedade e que deseja substituí-la como totalidade" (TENÓRIO; ARAÚJO, 2020, p. 892). Ou seja, a gestão social contrapõe-se ao tipo de gestão centrada no cálculo, em interesses individuais e na relação competitiva dos indivíduos uns com os outros: “(...) o outro é o concorrente, deve ser excluído e o lucro é o seu motivo" (TENÓRIO, 2008a, p. 159). Assim entendido, um conceito gerencial ancorado em valores democráticos que conduza o agir não pela res privata, como preconiza a sociedade de mercado, mas pela res publica, que constrói a dimensão da cidadania e do bem comum (TENÓRIO, 2010; TENÓRIO; ARAÚJO, 2020).

Mesmo na ausência de um denominador comum sobre a definição de gestão social, alguns pressupostos comuns podem ser identificados: (1) postura ética na conduta de suas ações; (2) valorização da transparência na gestão; (3) ênfase sobre a democratização das decisões e nas relações em organizações (FRANÇA FILHO, 2008); (4) interesse coletivo de caráter público; (5) subordinação da lógica instrumental a um processo decisório deliberativo, visando a atender às necessidades de um determinado sistema social; (6) reconhecimento da sociedade como protagonista da gestão; (7) processo participativo, dialógico e consensual e, (8) deliberação coletiva e processo discursivo livre com a força do melhor argumento (PIMENTEL; PIMENTEL, 2010).

Neste estudo gestão social é entendida como um processo dialógico, no qual a autoridade decisória é compartilhada entre os diferentes participantes da ação visando ao bem comum. Sob a atuação da ação comunicativa, na gestão social o indivíduo busca motivar o outro para que este concorde com o seu argumento, com a linguagem sendo utilizada como fonte de integração social (TENÓRIO, 2008a).

Essa definição de gestão social encontra fundamento na teoria da ação comunicativa de Jürgen Habermas como um processo dialógico, no qual todos os participantes da ação admitem sua validade, ou seja, a verdade é um acordo alcançado por meio da discussão crítica, da apreciação intersubjetiva. (TENÓRIO, 2008b, 2012). A ação comunicativa constitui uma ação orienta- 
da ao entendimento, capaz de promover a integração social entre os sujeitos participantes, por meio do uso da linguagem intersubjetivamente compartilhada. Com isso, a ação comunicativa contrapõe-se a uma ação estratégica, sustentada no egocentrismo e na busca do êxito, do alcance dos interesses privados (HABERMAS, 1994).

É no âmbito do processo de tomada de decisão coletiva que a gestão social se desenvolve, tendo como base a inteligibilidade da linguagem e o diálogo entre os participantes no estabelecimento da ação comunicativa, direcionada para o interesse público não estatal e para a realização do bem comum. Os atores sociais, dessa forma, sistematizam os saberes alternativos oriundos das esferas privadas, avaliam o provimento dos serviços públicos, reivindicam direitos, cobram ações do Estado e, com isso, fortalecem o campo político das esferas públicas (CANÇADO; PEREIRA; TENÓRIO, 2013).

De acordo com o pensamento habermasiano, a esfera pública é entendida como um espaço de formação da opinião pública gerada a partir da inserção da sociedade no processo discursivo, no qual o diálogo constitui o elemento privilegiado na defesa de argumentos orientados para fins comuns. Isso é possível porque há canalização de problemáticas do mundo da vida - responsável pela constituição de redes de comunicação que acabam por promover a socialização entre os cidadãos - para a esfera pública e, dessa maneira, conseguem pressionar e causar influência na tomada de decisão política pelo Estado (HABERMAS, 2003).

Assim, a esfera pública é considerada uma categoria-chave para a prática da democracia deliberativa expressa na relação entre Estado e sociedade. Constitui um espaço de formação democrática da vontade política, no qual são tematizadas e fundamentadas questões da vida pública e social. Por ser caracterizada como uma esfera de comunicação, os participantes procuram discutir e resolver problemáticas comuns que afetam as suas vidas por meio do entendimento e do consenso (LUBENOW, 2010).

A deliberação é legitimada pela estrutura discursiva de um processo público de formação da opinião e da vontade política. O objetivo da deliberação é justificar as decisões a partir de razões que todos poderiam aceitar; é fornecer um conjunto de razões que poderiam ser aceitas por todos os possíveis atingidos, ainda que nem todos compartilhem do tema ou assunto em questão (LUBENOW, 2010, p. 245).

Sustentada em tal discussão, a gestão social alinha-se ao conceito de cidadania deliberativa pela perspectiva habermasiana entendida como "sendo um tipo de cidadania embasado em um estilo político específico e em uma prática de democracia deliberativa, mediada por outros conceitos como agir comunicativo e racionalidade comunicativa" (SALGADO et al, 2019, p. 829). Em linhas gerais, segundo Tenório et al (2008), significa dizer que a "legitimidade das decisões políticas deve ter origem em processos de discussão, orientados pelos princípios da inclusão, do pluralismo, da igualdade participativa, da autonomia e do bem comum" (p. 9).

Nesse sentido, pode-se afirmar que a gestão social possui relação direta com a dimensão da cidadania e a participação da sociedade em espaços públicos, sobretudo sua prática tende a ser fortalecida sob o enfoque territorial por meio dos aspectos identitários e do sentido de pertencimento entre os indivíduos, o que contribui para a integração social. A participação cidadã na gestão social garante o protagonismo da sociedade no processo deliberativo, juntamente com o Estado, no papel de planejar e tomar decisões capazes de promover o desenvolvimento orientado para o bem-estar comum (CARRION; CALOU, 2008). 


\section{METODOLOGIA DA PESQUISA}

De natureza qualitativa, este estudo assume características exploratória e descritiva. Exploratória, tendo em vista que não se verificou a existência de estudos empíricos similares que abordam a temática, e descritiva por expor características de determinada população ou fenômeno e por visar a descobrir a existência de associações entre variáveis (GIL, 2002), por exemplo, o papel da participação da sociedade civil no processo de anexação de um território a outro município.

Como método de pesquisa, utilizou-se o estudo de caso único, uma investigação detalhada e profunda para gerar conhecimento acerca de um tema (GIL, 2002). A escolha pela unidade de análise levou em consideração um aspecto importante: ser uma das poucas experiências recentes de anexação do país, além de o tema ser pouco estudado a partir da literatura do Campo de Públicas.

A fim de alcançar os quatro objetivos específicos do trabalho, foram utilizadas diferentes estratégias de coleta de dados. Para apresentar a trajetória de mobilização e organização social a partir da percepção dos moradores (i); caracterizar a relação dos moradores do distrito Califórnia com o município de Volta Redonda (ii); e para identificar os principais desdobramentos provenientes do processo de anexação para o distrito Califórnia (iii), foram realizadas entrevistas semiestruturadas com representantes das associações de moradores do distrito que atuaram na elaboração e acompanhamento do Projeto de Lei 733/2011, além da análise de reportagens vinculadas pela mídia local sobre o referido processo de anexação.

Por sua vez, para evidenciar a atuação do poder público municipal em relação ao pleito dos moradores pela nova conformação territorial (iv), fez-se uso de uma ampla pesquisa documental realizada, sobretudo, em consultas às legislações, decretos, portarias, site institucional das prefeituras, do governo do Estado e da Assembleia Legislativa, além dos arquivos disponibilizados pelas associações de moradores do distrito Califórnia.

Ao todo foram realizadas 11 entrevistas com representantes de associações de moradores de três bairros do distrito (Fátima, Califórnia e Cerâmica União), observando-se que parte dos entrevistados está envolvida com as associações desde a década de 90. A fim de preservar a identidade dos respondentes e para melhor compreensão da análise definiu-se os seguintes códigos de identificação dos entrevistados: AC para representantes da associação de moradores do bairro Califórnia; AU para representantes da associação do bairro Cerâmica União e AF para representantes da associação de moradores do bairro de Fátima.

Os dados foram tratados por meio da análise de conteúdo, técnica usada para descrever e interpretar o conteúdo dos textos, facilitando a interpretação das mensagens e a compreensão de seus significados num nível que vai além da leitura comum (MORAES, 1999). Neste estudo, as categorias de análise foram definidas por meio da grade mista, ou seja, elas foram definidas preliminarmente com base na literatura e em evidências empíricas iniciais sobre o tema, porém admitiu-se a inclusão de categorias durante o processo de análise dos dados. A grade mista pareceu ser a mais pertinente tendo em vista o caráter exploratório do estudo (VERGARA, 2010).

As categorias de análise são: 1) conformação territorial entendida como o processo de delimitação do território; 2) identidade e pertencimento considerados os elementos simbólicos ou concretos internalizados pelos atores sociais para a existência do território; 3) participação 
social como elemento da gestão social resultante de uma prática de mobilização política e organização social na reivindicação de problemáticas e autoridade decisória compartilhada e, 4) influência política que diz respeito à atuação dos governos locais no processo de anexação.

Numa abordagem qualitativa com diferentes técnicas de coleta de dados, o uso da triangulação destes proporciona uma maior confiabilidade dos resultados. Assim, durante a análise dos resultados a triangulação foi utilizada com o propósito de reduzir o risco de conclusões enviesadas ou limitadas, próprias de uma única fonte de dados, e para reforçar a validade dos resultados encontrados.

\section{DISCUSSÃO E ANÁLISE DOS RESULTADOS}

Os resultados serão apresentados de acordo com as categorias previamente estabelecidas, sempre de forma articulada com a discussão teórica, a fim de reconhecer os motivos que conduziram a população do distrito Califórnia almejar a anexação ao município vizinho e entender o papel da participação social neste processo.

\section{Conformação Territorial}

Até meados da década de 50 do século 20 Volta Redonda era um distrito pertencente ao município de Barra Mansa, um dos maiores e até então um dos mais desenvolvidos do sul fluminense. A partir de 1941, com a instalação da Companhia Siderúrgica Nacional (CSN) em Volta Redonda, a região cresceu e se desenvolveu rapidamente, refletindo no surgimento nos primeiros esforços e movimentos políticos para sua emancipação, que viria a ocorrer 13 anos mais tarde, em 1954.

O protagonismo econômico e social de Volta Redonda em relação aos municípios vizinhos refletiu-se no crescimento populacional - maior cidade do sul fluminense - e na circulação de moradores de outros municípios para utilizar serviços públicos, comércio e para ingressar no mercado de trabalho.

Já o distrito Califórnia possui 20 mil habitantes, o que representa $25 \%$ da população total do município-sede, Barra do Piraí (IBGE, 2020). O distrito é composto por 11 bairros e está localizado a 36,1 km de distância do centro de Barra do Piraí. Essa distância faz com que os moradores tenham dificuldade e resistência de se locomover até a região central da cidade, julgando mais cômodo e rápido descolar-se para Volta Redonda, uma vez que o distrito faz divisa com o município vizinho e está a 6 quilômetros do centro de Volta Redonda.

A distância impacta diretamente a logística e o custo de deslocamento para ambos os centros, uma vez que o transporte público para Volta Redonda é mais acessível economicamente, além do tempo reduzido para se chegar lá: “Por que você com dez ou quinze minutos está em Volta Redonda, seja qual for o horário. Já para Barra do Piraí você depende de uma condução mais cara, tem pedágio e é longe" (AU2).

Para além da proximidade geográfica, parte significativa dos moradores do distrito utilizam serviços públicos da cidade vizinha - como saúde, educação e assistência social - e também votam, trabalham e recorrem ao comércio de Volta Redonda. Ademais, a prefeitura de Volta Redonda estendeu o transporte público municipal até o distrito, e é responsável pela provisão dos 
serviços de água e esgoto e parte da rede elétrica do distrito Califórnia, por meio de contratos com a prefeitura de Barra do Piraí.

Somam-se a estes fatores as recorrentes queixas da insuficiência de serviços públicos no distrito, principalmente relacionados à saúde e educação, diante de uma população com mais de 20 mil habitantes. Em todo o distrito Califórnia, no ano de 2017 havia duas Unidades Básicas de Saúde (UBS), duas escolas municipais e um Centro de Referência Municipal de Assistência Social (Cras) (BARRA DO PIRAÍ, 2017). A insuficiente provisão de serviços públicos influenciou, sobremaneira, a vontade dos moradores de pertencer ao município limítrofe:

Se Barra coloca os serviços públicos que o morador espera, precisa e merece, porque também paga os impostos, ninguém vai lembrar de buscar essas coisas em Volta Redonda. Vamos ter tudo aqui. Esse sentimento vem com a ausência de serviços públicos (AC).

(...) Tudo se resolve em Volta Redonda, água, luz, telefone, o pessoal trabalha... o transporte, educação, saúde. Tudo gira em torno da cidade de Volta Redonda. E aí a coisa chegou a esse ponto, da gente não querer mais pertencer a Barra do Piraí, de sermos cidadãos de Volta Redonda (AU1).

A prefeitura de Barra do Piraí possui a Secretaria Municipal do Complexo da Califórnia e São José do Turvo, com atribuições semelhantes à de uma subprefeitura, com foco na manutenção e garantia da instituição de políticas públicas na localidade. Mesmo com a Secretaria, no entanto, o governo municipal parece não priorizar a região, dado o número insuficiente de equipamentos públicos na localidade. Este é o sentimento geral da população que lá habita.

Em suma, o cotidiano do barrense residente no distrito Califórnia baseia-se, em grande medida, em uma rotina que envolve o território volta-redondense. "A Califórnia é considerada só como dormitório de Volta Redonda", relatou o entrevistado AF, devido ao fato de que todas as suas atividades e necessidades serem irrealizadas na cidade vizinha. Tal relato guarda relação com o que Cazella, Bonnal e Maluf (2009) discorrem acerca da construção de um território por meio do uso social, além de ser resultado das ações concretas pelos atores sociais (MADOERY, 1999).

\section{Identidade e Pertencimento ao Território}

A identificação com o local é fundamental na construção de um território que fomente o sentimento de pertencimento e o uso da terra coletivamente de forma integrada (SCHEJTMAN; BERDEGUÉ, 2004). O sentimento relacionado à identidade pode ser despertado na vida dos habitantes de diferentes formas e, no caso aqui analisado, para além da proximidade com o município vizinho, ele está relacionado à escassez da provisão de serviços públicos por parte da prefeitura de Barra do Piraí e do dinamismo em Volta Redonda.

$\mathrm{Na}$ análise das entrevistas, verificou-se que a identidade do residente do distrito Califórnia está associada a vínculos preexistentes com o município vizinho. Isso porque parte dos moradores era, antes, residente em Volta Redonda. Por razões diversas - fugir da poluição, maior segurança e imóveis com preços mais acessíveis - essas pessoas optaram pela mudança de endereço, tornando Barra do Piraí uma "cidade-dormitório", na medida em que as atividades diárias continuaram sendo realizadas na cidade adjacente. Nas palavras do entrevistado AF, "nós somos filhos de Volta Redonda". 
Como resultado, a relação dos moradores do distrito com Barra do Piraí não se configura a noção de um território, que pressupõe a construção do sentimento de pertencimento local (HAESBAERT, 2004) e um espaço de identificação. Não há, portanto, a compreensão de um território construído referente ao espaço no qual estão inseridos: a concepção de território ocorre apenas de forma institucional, de espaço geográfico delimitado.

Apesar do frágil sentimento de pertencimento e da atuação questionável da prefeitura na região, os entrevistados foram unânimes ao relatar que gostam de onde moram: "Nós gostamos de onde moramos, da nossa comunidade, mesmo com a situação a gente ama esse lugar. E se for colocar em questão não o bairro, mas a cidade a que a gente pertence, aí a situação é bem complicada" (AC1).

Os conceitos "território dado" e "território construído" (PECQUEUR, 2005) também contribuem com a discussão pelo prisma territorial e de pertencimento. Uma vez que a delimitação geográfica e político-administrativa do distrito Califórnia no município de Barra do Piraí associa-se à ideia de "território dado", a noção de pertencimento dos moradores ao município de Volta Redonda está atrelada a um "território construído", dado o vínculo diário dos moradores com a Cidade do Aço (nome popular dado à Volta Redonda em alusão à siderúrgica CSN).

Ao fim e ao cabo, o fato de o distrito fazer fronteira e estar a poucos quilômetros da região central de Volta Redonda possibilita que os cidadãos barrenses tenham conhecimento e comparem as duas realidades locais e, consequentemente, a preferência será por aquela que apresentar melhor acesso e qualidade dos serviços públicos:

Barra do Piraí tem um recurso e Volta Redonda tem outro. A gente vive aqui olhando lá e querendo as coisas que tem lá. Volta Redonda tem um posto de saúde e uma praça em todo bairro. Eu acho que proporcionalmente nós poderíamos estar melhores por meio de Barra do Piraí (AC).

\section{Participação Social}

O desejo de mudança não é novo nos discursos da população barrense: os primeiros esforços da comunidade relacionados ao processo de anexação datam da década de 80 e, segundo os entrevistados, com amplo envolvimento da população local. Isso nos faz refletir acerca do elemento político, ou seja, da dimensão do poder no conceito de participação, seja quando se pretende enfrentar o Estado na busca de autoafirmação coletiva, seja na tentativa de construção de uma identidade como ator político (TEIXEIRA, 2002). Além disso, a ação coletiva possui uma voz mais expressiva se comparada à luta individual, além de fomentar a formação de um território como uma construção social a partir de suas múltiplas dinâmicas - econômicas, sociais, políticas e culturais - consideradas específicas de cada territorialidade (SCHEJTMAN; BERDEGUÉ, 2004; CAZELLA; BONNAL; MALUF, 2009).

No esforço de reconstruir a trajetória do processo de desmembramento e anexação, os representantes das associações de bairro recordaram de algumas iniciativas com protagonismo da sociedade civil. 0 primeiro esforço ocorreu na década de 80 , com a organização de um abaixo-assinado encaminhado à Assembleia Legislativa do Estado do Rio de Janeiro (Alerj) que resultou no encaminhamento e aprovação, na Câmara Municipal de Volta Redonda, de uma resolução que anexava o distrito Califórnia ao município vizinho. Com a redemocratização e a 
promulgação da Constituição Federal de 1988, no entanto, os processos de anexação e emancipação passaram a exigir plebiscito, com ampla participação social.

Nos anos 90 houve uma segunda mobilização popular quando os 11 bairros que hoje formam o distrito Califórnia ainda pertenciam ao distrito de São José do Turvo. Naquela época já existia a vontade de anexação a Volta Redonda, mas, por ser um processo complexo, demorado e permeado de interesses políticos, a anexação foi convertida em emancipação. De acordo com um entrevistado, no decorrer desse processo a população e o poder público chegaram ao consenso de que a emancipação seria mais factível e realista, se contasse com o envolvimento e o apoio da população durante o plebiscito. A emancipação, contudo, não era o verdadeiro anseio dos cidadãos e, por consequência, o engajamento popular foi inferior ao esperado:

O plebiscito foi para a emancipação. Mudamos de anexação para emancipação. [...] Não teve êxito na ocasião por falta de quórum, não teve numero suficiente de eleitores nas urnas, então a Califórnia não se emancipou (AC).

No período que antecedeu o plebiscito sobre emancipação dos bairros que hoje formam o distrito Califórnia, o engajamento das lideranças locais foi fundamental. De acordo com as entrevistas, as associações de bairros, juntamente com a Igreja Católica, organizaram e lideraram todo o processo.

Tinham reuniões, tinha um programa de rádio que divulgava as reuniões que fazíamos com os vereadores e também com o deputado federal que participava juntamente com a mobilização da população. Naquela ocasião houve um movimento muito forte da Igreja Católica - o precursor dessa história. Eles abraçaram esse processo de emancipação. E no dia da eleição infelizmente faltaram votos, sendo o projeto arquivado (AC1).

Somente em 2011 o processo de anexação voltou a ser foco das mobilizações sociais, quando em uma reunião na Associação de Moradores da Califórnia, com a presença de representantes de todos os bairros do distrito, chegou-se ao consenso de que os problemas locais, principalmente os relacionados à falta de serviços públicos essenciais, só seriam solucionados com a anexação ao município vizinho. Nesta reunião foi criado e aprovado o movimento "ANEXAÇÃO JÁ!"

O movimento teve apoio de parte do Legislativo estadual e, ainda em 2011, foi apresentado à Alerj o Projeto de Lei de 733/2011, que visava ao desmembramento dos 11 bairros que compõem o Complexo Califórnia e sua anexação ao município de Volta Redonda, contando com a realização de plebiscito com a população interessada.

Conforme o Projeto de Lei, a anexação se justifica pelo fato de 1) o distrito Califórnia fazer divisa com Volta Redonda, localizando-se mais perto do município vizinho do que do centro de Barra do Piraí; 2) por grande parte da população ter sua vida diária baseada em Volta Redonda e, 3) no grande anseio dos moradores do distrito de pertencerem à Cidade do Aço. As justificativas contidas no Projeto de Lei corroboram os motivos aqui já discutidos.

Em setembro do mesmo ano, cerca de 2 mil moradores do Distrito Califórnia participaram de um encontro com políticos locais para se atualizarem a respeito da tramitação do Projeto de Lei. Nesta ocasião, os políticos reforçaram a importância de o movimento "ANEXAÇÃO JÁ" ter nascido do engajamento da comunidade, sendo eles os principais beneficiados com a anexação. Este encontro, segundo os entrevistados, fez com que a população acreditasse na concretização da mudança, uma vez que havia mobilização social e vontade política de parte do Legislativo. 
Nesse período, era comum integrantes das associações viajarem para o Rio de Janeiro e Brasília em busca de apoio de deputados estaduais e federais na tramitação do Projeto de Lei. Até meados de 2014 o clima era de confiança.

Sobre tal discussão destaca-se a mobilização e a organização social como instrumentos da participação cidadã sendo capaz de expressar necessidades perante o Estado. O fortalecimento e a efetividade da organização social estão relacionados com a representatividade dos seus membros; a legitimidade do processo participativo; a participação da base refletida em mobilização; a autossustentação que passa por compromisso participativo e engajamento político (DEMO, 1988).

Em 2015, o presidente da Alerj alterou e substituiu o Projeto de Lei 733/2011 pela Lei no 7009/2015, que determinou novos limites territoriais de Volta Redonda e Barra do Piraí (ASSEMBLEIA..., 2015), ignorando a obrigatoriedade da realização de plebiscito, conforme estipula a Constituição de 1988. Essa "saída" só foi possível porque o presidente da Alerj tratou a questão não como anexação, mas sim como alteração dos limites de fronteiras entre os municípios. A lei foi vetada, teve o veto quebrado pela Alerj e, por fim, foi tida como inconstitucional pelo Tribunal de Justiça do Estado do Rio de Janeiro em 2016, tendo seus efeitos suspensos.

$\mathrm{O}$ não atendimento às prerrogativas constitucionais foi reconhecido pela maioria dos entrevistados, que mesmo antes de sair a decisão do Tribunal de Justiça já era por eles imaginada. A inconstitucionalidade, segundo nos foi relatado, explica o desânimo da população quanto à efetividade futura da anexação. Para parte dos representantes das associações de moradores, o processo de anexação está encerrado e indiscutível dentro na agenda pública. Mesmo, no entanto, com o cansaço decorrente de anos de luta, como eles assim caracterizam, a vontade de anexação ainda está presente:

(...) a gente continua com a mesma esperança desde lá em 2007, 2012, 2015, estamos na mesma sintonia, não diminuiu de forma alguma. Em nosso pensamento e nosso coração acreditamos que vai acontecer essa obra grandiosa (AU1).

O processo [de anexação] eu não acredito mais, só que se voltar eu vou lutar, claro (AU2).

Conforme já exposto, a demanda pela anexação emergiu da vontade popular com protagonismo das associações de moradores. O papel das associações foi fundamental, pois elas conseguiram reunir e levar até o poder público as demandas locais que muitas vezes são ignoradas pela administração pública. Tal questão guarda relação com o processo de discussão e inclusão como critérios definidores da gestão social, pois possibilitam a reivindicação de necessidades coletivas entendida como a capacidade em expressar as carências e demandas dos grupos sociais aos quais pertencem (TENÓRIO et al., 2008).

Soma-se a isso a interface com o conceito de esfera pública (HABERMAS, 2003) como um espaço político que funciona como uma caixa de ressonância, em que os problemas oriundos do mundo da vida a serem trabalhados pelo sistema político ganham eco. A função exercida pela esfera pública direciona-se para a percepção e a identificação dos problemas da sociedade, além da problematização, a ponto de serem colocados em evidência pelo sistema político.

Os entrevistados, todavia, apontam algumas resistências do poder público de Barra do Piraí em estabelecer um espaço de diálogo com as associações de moradores, enquanto atores e parte da sociedade civil: "o poder público daqui tem uma dificuldade muito grande em atender 
o povo da Califórnia, principalmente as associações de moradores" (AU1). A longa distância até o centro da cidade também dificulta o diálogo constante.

Tal resistência do poder local opõe-se ao que Jacobi (2002) pondera acerca dessas organizações comunitárias serem incorporadas nas atividades desenvolvidas pela administração pública. Também pode ser analisada uma postura de caráter vertical nas decisões de interesse público, o que inviabiliza a gestão social e a possibilidade da sociedade sentir-se verdadeiramente parte da construção política (TENÓRIO; ROZENBERG,1997). É no âmbito do processo de tomada de decisão coletiva que a gestão social se desenvolve, tendo como base a inteligibilidade da linguagem e o diálogo entre os participantes no estabelecimento da ação comunicativa, direcionada para a realização do bem comum (CANÇADO; TENÓRIO; PEREIRA, 2011).

Outra dificuldade apontada pelos entrevistados consistiu na limitada participação da população nas reuniões e nas atividades promovidas pelas associações de moradores. Tal ausência pode estar relacionada à apatia política e à descrença na representatividade pelas associações de moradores.

Apesar do baixo envolvimento da comunidade nos espaços de discussão em prol do coletivo, durante o processo de anexação o envolvimento e a participação foram expressivamente positivos. Tal fato dialoga com Tenório e Rozenberg (1997), ao apontarem que a participação acontece quando os indivíduos se unem e desejam de forma organizada e coletiva buscar soluções para problemas comuns.

Nós levamos dez ônibus em uma audiência pública em Volta Redonda, todos eles lotados, todos aqui do distrito. Comenta-se em Volta Redonda, na Câmara de Vereadores, que foi a maior audiência pública realizada na cidade até hoje. Então você vê a quantidade de pessoas que participavam na ocasião. Em todo momento no auge da anexação, que foram dois anos e meio, quase três anos, nós fizemos carreata na Califórnia de ter aí mil carros, mil e quinhentos carros, passeatas lotadas. Então houve naquele momento uma participação da comunidade, dos moradores, muito grande (AU1).

Tem propriamente uma coisa inerente aqui da nossa comunidade, que conseguiu realmente unificar o sentimento, o desejo, foi o momento de anexação. Ali vi em cada ponto aqui do distrito Califórnia favorável a esse desejo de anexar a Volta Redonda né. (...) Que viram como a única forma de melhoria para cá (AC).

Após a inconstitucionalidade e a compreensão de que a anexação já não fazia parte da agenda do governo, no entanto, a participação "voltou à estaca zero" conforme relatou o entrevistado AC. Os representantes apontam que o esvaziamento é resultado da decepção e da descrença dos cidadãos diante de um processo praticamente certo, conforme era transmitido pelos jornais locais e nas próprias reuniões nas associações de moradores.

Nós acreditávamos piamente que ia ser anexada (...), a população tinha uma ansiedade maior, a participação foi muito boa; o povo contava realmente que nós já éramos Volta Redonda. O povo ficou muito, muito triste. A gente ficou com tanta vergonha que nem gosta de comentar mais (AU2).

De forma geral, pode-se perceber nas falas dos entrevistados as dimensões pedagógica, de expressão política e social da participação como forma de fortalecimento da atuação democrática e da prática cidadã pela população local (TEIXEIRA, 2002), contudo a dinâmica do encaminhamento das decisões pelas instituições impediu a prática da gestão social sustentada 
na dialogicidade e na deliberação pelo protagonismo da sociedade civil, o que resultou em uma ação estratégica de tomada de decisão (TENÓRIO, 2008b).

\section{Influência Política}

Para uma análise abrangente do caso em tela, faz-se necessário abordar o posicionamento dos governos locais e a influência política nos meandros do processo de anexação.

No que se refere aos representantes dos poderes Executivo e Legislativo de Barra do Piraí, segundo os entrevistados, em alguns momentos mostraram-se favoráveis aos anseios da população e, em outros, não se percebia engajamento político acordado. Numa análise crítica sobre as possíveis perdas com a anexação, contudo, acredita-se que os políticos locais não viam a diminuição do município com bons olhos, na medida em que Barra do Piraí perderia $1 / 4 \mathrm{de}$ seus habitantes, além de parte significativa do principal imposto municipal, o Imposto Predial e Territorial Urbano (IPTU). O IPTU é a principal fonte de recursos próprios para grande parte dos municípios brasileiros.

A análise dos entrevistados corrobora esse entendimento. Foi consensual a percepção de que mesmo que os políticos não tenham se posicionado contrários à anexação, não houve nenhuma ação liderada pela prefeitura ou pela Câmara dos Vereadores que indicasse um apoio à população do distrito Califórnia em alcançar seu desejo.

Os vereadores não apoiavam muito não, eles ficavam em cima do muro. Eles não iam falar pra anexar, perder a população pra Volta Redonda. O próprio prefeito deu uma entrevista dizendo que não achava bom passar, não, se mostrou contra, mas que respeitava a vontade da população (AC3).

Já na cidade vizinha o posicionamento era o oposto: "em Volta Redonda recebiam a gente de braços abertos, demonstraram muito apoio" (AC3). Isso porque, com a anexação, o município iria aumentar sua receita própria e, como grande parte dos moradores do distrito já utilizavam os serviços públicos do município, a anexação não refletiria um aumento significativo nas demandas de serviços como saúde e educação, por exemplo.

Os entrevistados relataram que durante o processo a prefeitura de Barra do Piraí não promoveu nenhuma mudança expressiva dentro do distrito Califórnia para tentar reverter esse sentimento, ou seja, não houve melhora dos serviços públicos e nem no atendimento quanto aos representantes das associações de moradores. Tal postura só criou uma comparação ainda maior com o município de Volta Redonda, que "sempre se posicionou de braços abertos" (AC).

Ao serem questionados sobre a atual situação do distrito Califórnia, ou seja, se a insatisfação que deu início a toda mobilização social persiste nos dias atuais, foi consenso entre os entrevistados a falta de atenção à região por parte da gestão municipal de Barra do Piraí. Os entrevistados, porém, apontaram algumas ações que aproximaram o distrito do restante do município, fato que pode, em longo prazo, aumentar o sentimento de pertencimento com o município ao qual estão institucionalmente vinculados.

Nós temos vários problemas aqui na Califórnia, que a prefeitura deixa a desejar. Mas o novo prefeito [gestão 2016-2020] já fez a mudança no ônibus para Barra, com mais horários e baixando o preço da passagem, que tem a intenção de dar esse sentimento ao morador da 
Califórnia de ser barrense, tomara que ele consiga. [...] O movimento em si não teve êxito na anexação, mas teve êxito em chamar atenção para Barra do Piraí. [...] Os vereadores estão mais atentos nos projetos de lei $(A C)$.

(...) mudou porque nessa gestão a gente está tendo um trabalho social maior (AU2).

Se melhorar aqui não vão querer anexar (AU3).

Conforme os relatos, a gestão municipal está mais atenta ao distrito Califórnia, numa aproximação maior com a população. Para além do apelo popular, essa aproximação da prefeitura pode ser resultado da atuação de vereadores oriundos do distrito Califórnia, que foram eleitos em maior número na última eleição municipal. O fato de o distrito estar representado no Legislativo municipal aumenta as expectativas da comunidade de ter seu território contemplado nas políticas públicas.

Assim como destaca Raffestin (1993), a dinâmica do território é (re)construída pela marcação do espaço e das relações de poder que ali são estabelecidas pelos atores sociais. No caso do distrito Califórnia, novas territorialidades podem ser constituídas pelas relações de poder características da gestão pública e da relação estabelecida com a população local como resultado de processos políticos e sociais que caracterizam o território em um contexto histórico (SAQUET, 2008).

\section{CONSIDERAÇÕES FINAIS}

O artigo evidencia a mobilização e a organização social, sobretudo pelas associações de moradores, no processo de anexação do distrito Califórnia localizado em Barra do Piraí ao município de Volta Redonda. Como afirma um dos entrevistados: "Tem propriamente uma coisa inerente aqui da nossa comunidade, o que conseguiu realmente unificar o sentimento, o desejo, foi o momento de anexação (..)" (AC). Tal afirmação dialoga diretamente com Tenório e Rozenberg (1997), ao apontarem que a participação acontece quando os indivíduos se unem e se organizam de forma coletiva, a fim de buscar soluções para questões comuns.

Nesse sentido, após a menção à inconstitucionalidade do processo e a compreensão de que este está encerrado, a participação da população "voltou à estaca zero". Sobre isso, os entrevistados alegam que a população ficou frustrada diante de tal contexto porque a anexação era algo já garantido, assim como foi transmitido pelos jornais e nas próprias reuniões que realizavam. "Nós acreditávamos piamente que ia ser anexada (...), a população tinha uma ansiedade maior, a participação foi muito boa; o povo contava realmente que nós já éramos Volta Redonda. O povo ficou muito, muito triste" (AU2).

A análise do processo participativo sob o enfoque territorial contribui para a discussão sobre o sentido de pertencimento que deve ser apropriado e reconhecido pela população local ao invés da conformação do território somente por critérios político-administrativos. No caso do distrito Califórnia, o anseio da população local guarda relação com o contexto histórico marcado pela mobilização social pela anexação, o que é explicado pelo aspecto geográfico que possibilita o deslocamento com maior facilidade e economicidade ao município vizinho, mas também pela melhor prestação de serviços públicos em Volta Redonda quando comparado com Barra do Piraí. 
Outro ponto de destaque diz respeito à fragilidade no diálogo entre o poder público de Barra do Piraí e a sociedade civil no que respeita à reivindicação pela anexação encaminhada pelas associações de moradores do distrito Califórnia, o que compromete a gestão social como um processo gerencial dialógico no qual a autoridade decisória é compartilhada entre os diferentes participantes da ação em uma esfera pública (TENÓRIO, 2008b).

Soma-se a isso o fato de que para além da participação social que fomentou a mobilização e a organização social pela anexação como elementos da gestão social, deve-se considerar o conjunto de forças políticas no âmbito do Executivo e Legislativo na defesa de interesses que impactam a governança local, como a perda de arrecadação tributária para o município vizinho.

\section{REFERÊNCIAS}

ASSEMBLEIA LEGISLATIVA DO ESTADO DO RIO DE JANEIRO. Projeto de Lei 733/2011. Disponível em: http://alerjln1.alerj.rj.gov.br/scpro1115.nsf/18c1dd68f96be3e7832566ec0018d833/07ce9aa47729221 a832578e7006f3a26?OpenDocument. Acesso em: 10 fev. 2019.

ASSEMBLEIA LEGISLATIVA DO ESTADO DO RIO DE JANEIRO. Lei Ordinária 7009/2015. Disponível em: http://alerjln1.alerj.rj.gov.br/contlei.nsf/b24a2da5a077847c032564f4005d4bf2/08e58b5fc3b4dfc583257e51005e7d39?OpenDocument Acesso em: 10 fev. 2019.

BARRA DO PIRAÍ. Portal da Prefeitura: Califórnia da Barra. Disponível em: https://www.barradopirai.rj.gov. $\mathrm{br} /$ portal/index.php?option=com_content\&view=article\&id=129\&Itemid=249. 2017. Acesso em: 4 nov. 2021.

BONNAL, P.; DELGADO, N. G.; CAZELLA, A. Subsídios metodológicos ao estudo do desenvolvimento territorial rural. In: MIRANDA, C.; TIBÚRCIO, B. (org.). Políticas públicas, atores sociais e desenvolvimento territorial no Brasil. Brasília: IICA, 2011. p. 35-60. (Série Desenvolvimento Rural Sustentável, v. 14).

BORDENAVE, J. E. D. O que é participação? São Paulo: Editora Brasiliense, 1983.

BOULLOSA, R. F.; SCHOMMER, P. C. Gestão social: caso de inovação em políticas públicas ou mais um enigma de Lampedusa. In: RIGO, A. S.; SILVA JUNIOR, TORRES, J.; SCHOMMER, P. C.; CANÇADO, A. C. (org.). Gestão social e políticas públicas de desenvolvimento. Ações, articulações e agenda. Recife: Univasf, 2010. CANÇADO, A. C.; PEREIRA, J. P.; TENÓRIO, F. G. Gestão social: epistemologia de um paradigma. Curitiba: CRV, 2013.

CANÇADO, A.; TENÓRIO, F. G.; PEREIRA, J. R. Gestão social: reflexões teóricas e conceituais. Cad. EBAPE. $B R$, Rio de Janeiro, v. 9, n. 3, p. 681-703, 2011.

CARRION, R.; CALOU, A. Pensar a gestão social em terras de "Padinho Cícero". In: SILVA JR., J. T.; MÂISH, R. T.; CANÇADO, A. C. (org.). Gestão social: práticas em debate, teorias em construção. Fortaleza: Imprensa Universitária, 2008.

CAZELLA, A.; BONNAL, P.; MALUF, R. Olhares disciplinares sobre território e desenvolvimento territorial. In: CAZELLA, A.; BONNAL, P.; MALUF, R. Agricultura familiar: multifuncionalidade e desenvolvimento territorial no Brasil. Rio de Janeiro: Mauad X, 2009.

COELHO, F. S. Prefácio. In: CANÇADO, A. C.; PEREIRA, J. R.; TENÓRIO, F. G. (org.). Gestão social: epistemologia de um paradigma. Curitiba: CRV, 2015.

DEMO, P. Participação e planejamento - arranjo preliminar. Revista de Administração Púbica, Rio de Janeiro, v. 25, n. 3, p. 31-54, jul./set. 1991.

DEMO, P. Participação é conquista. São Paulo: Cortez: Autores Associados, 1988.

FRANÇA FILHO, G. C. Definido gestão social. In: SILVA JR., J. T.; MÂISH, R. T.; CANÇADO, A. C. (org.). Gestão social: práticas em debate, teorias em construção. Fortaleza: Imprensa Universitária, 2008.

GIL, A. C. Como elaborar projetos de pesquisa. 4. ed. São Paulo: Atlas, 2002.

HABERMAS, J. Direito e democracia: entre facticidade e validade. Rio de Janeiro: Tempo Brasileiro, 2003. Vol. II.

HABERMAS, J. Derechos Humanos y Soberanía Popular: las concepciones liberal y republicana. Ratio Luris, v. 7, n. 1, p. 1-13, 1994.

HABERMAS, J. Teoría de la acción comunicativa. Crítica de la razón funcionalista. Madrid: Taurus Ediciones, 1987. V. II. 
HAESBAERT, R. Dos múltiplos territórios à multiterritorialidade. Porto Alegre, 2004. Disponível em: http:// www.ufrgs.br/petgea/Artigo/rh.pdf. Acesso em: 7 abr. 2020.

IBGE. Instituto Brasileiro de Geografia e Estatística. Cidades. Panorama Barra do Piraí. Disponível em: https://cidades.ibge.gov.br/brasil/rj/barra-do-pirai/panorama. Acesso em: 7 abr. 2020.

JACOBI, P. R. Políticas sociais locais e os desafios da participação citadina. Ciênc. Saúde Coletiva, v. 7, n. 3, p. 443-454, 2002.

LUBENOW, J. A. Esfera pública e democracia deliberativa em Habermas: modelo teórico e discursos críticos. Kriterion, Belo Horizonte, n. 121, p. 227-258, jun. 2010.

MADOERY, O. El territorio como factor estratégico de desarrollo. Hacia un espacio de gestión metropolitana en el Gran Rosario. Rosario, jun. 1999. (Serie Documentos de Trabajo, no 11). Disponível em: http:// www.conectadel.org/wp-content/uploads/downloads/2013/03/17MU1176.pdf. Acesso em: 6 abr. 2020.

MAIA, M. Gestão social: reconhecendo e construindo referenciais. Revista Virtual Textos \& Contextos, Porto Alegre, n. 4, a. IV, p. 1-18, dez. 2005.

MORAES, R. Análise de conteúdo. Revista Educação, Porto Alegre, v. 22, n. 37, p. 7-32, 1999.

PECQUEUR, B. O desenvolvimento territorial: uma nova abordagem dos processos de desenvolvimento para as economias do Sul. Raízes, Campina Grande, v. 24, n. 1 e 2, jan./dez. p. 10-22, 2005.

PIMENTEL, M. P. C.; PIMENTEL, T. D. Gestão social: perspectivas, princípios e (de)limitações. In: ENCONTRO DE ESTUDOS ORGANIZACIONAIS- ENEO, 6., 2010. Florianópolis. Anais [...]. Florianópolis: Anpad. 2010. p. 1-17.

PIRES, V. et al. Dossiê - Campo de Públicas no Brasil: definição, movimento constitutivo e desafios atuais. Administração Pública e Gestão Social, Viçosa, v. 6, n. 3, p. 110-126, 2014.

PREFEITURA DE BARRA DO PIRAÍ. Distrito Califórnia da Barra. Disponível em: https://www.barradopirai. rj.gov.br/portal/index.php?option=com_content\&view=article\&id=129\&ltemid=249. Acesso em: $7 \mathrm{abr}$. 2020.

RAFFESTIN, C. Por uma geografia do poder. São Paulo: Ática, 1993.

SALGADO, R. J. S. F. et al. Cidadania deliberativa e gestão social: revisão sistemática de literatura no Brasil. Cad. EBAPE.BR, Rio de Janeiro, v. 17, Edição Especial, p. 817-831, 2019.

SAQUET, M. A. Por uma abordagem territorial. In: SAQUET, M. A.; SPOSITO, E. S. Territórios e territorialidades: teorias, processos e conflitos. 1. ed. São Paulo: Expressão Popular: Unesp; Programa de Pós-Graduação em Geografia, 2008.

SCHEJTMAN, A.; BERDEGUÉ, J. A. Desarrollo territorial rural. Rimisp - Centro Latinoamericano para el Desarrollo Rural. Debates y Temas Rurales, n. 1, mar. 2004.

SOUZA, M. J. L. de. O território: sobre espaço e poder, autonomia e desenvolvimento. In: CASTRO, I. E.; GOMES, P. C. C.; CORREA, R. L. Geografia conceitos e temas. 2. ed. Rio de Janeiro: Bertrand Brasil, 2000.

TEIXEIRA, E. C. O local e o global: limites e desafios da participação cidadã. São Paulo: Cortez; Recife: Equip; Salvador: Ufba, 2002.

TENÓRIO, F. G. Tem Razão a Gestão Social? In: SEMINÁRIO DE GESTÃO SOCIAL E DESENVOLVIMENTO, 2., Projeto Pró-Administração/Capes. 2012. Florianópolis. Anais [...]. Florianópolis, SC, 22 e 23 nov. 2012. p. 1-17.

TENÓRIO, F. G. Descentralização político-administrativa, gestão social e participação cidadã. In: DALLABRIDA, V. R. (org.). Governança territorial e desenvolvimento: descentralização político-administrativa, estruturas subnacionais de gestão do desenvolvimento e capacidades estatais. Rio de Janeiro: Garamond, 2011.

TENÓRIO, F. G. Gestão social: uma réplica. In: RIGO, A. S.; SILVA JÚNIOR, J. T.; SCHOMMER, P. C.; CANÇADO, A. C. (org.). Gestão social e políticas públicas de desenvolvimento: ações, articulações e agenda. Recife: Univasf, 2010.

TENÓRIO, F. G. Tem razão a administração? Ensaios de teoria organizacional. 3. ed. rev. e ampl. Ijuí: Editora Unijuí, 2008a.

TENÓRIO, F. G. Um espectro ronda o terceiro setor: o espectro do mercado. Ensaios de gestão social. 3. ed. rev. e ampl. Ijuí: Editora Unijuí, 2008b.

TENÓRIO, F. G. A trajetória do Programa de Estudos em Gestão Social (Pegs). Revista de Administração Pública, Rio de Janeiro, v. 40, n. 6, p. 1.145-1.162, 2006.

TENÓRIO, F. G. et al. Critérios para a avaliação de processos decisórios participativos deliberativos na implementação de políticas públicas. In: ENCONTRO DE ADMINISTRAÇÃO PÚBLICA E GOVERNANÇA, 2008. Salvador. Anais [...]. Curitiba: Anpad, 2008. p. 1-16. 
TENÓRIO, F. G.; ARAÚJO, E. T. Mais uma vez o conceito de gestão social. Cad. EBAPE.BR, Rio de Janeiro, v. 18, n. 4, p. 891-905, out./dez. 2020.

TENÓRIO, F. G.; ROZENBERG, J. E. Gestão pública e cidadania: metodologias participativas em ação. Revista de Administração Pública, Rio de Janeiro, v. 31, n. 4, p. 101-125, 1997.

VERGARA, S. C. Métodos de pesquisa em administração. São Paulo: Atlas, 2010. 